\title{
Laparoscopic Sleeve Gastrectomy: Comparing Two Techniques
}

\author{
Mohamed Lasheen, MD; FACS; Mohamed Mahfouz MD, MRCS \\ Department of General Surgery, Ain Shams University, Cairo, Egypt
}

Sleeve gastrectomy is the fastest growing bariatric surgery nowadays. This is a prospective randomized study comparing two techniques in performing laparoscopic sleeve gastrectomy.

Methods: This is a prospective randomized study of 50 patients divided into 2 groups each of 25 , for whom laparoscopic sleeve gastrectomy was done between July 2016 and December 2016, with a follow-up period of 1 year.

Regarding the surgical technique in group $(A)$ dissection of the greater omentum was done till reaching the left crus of the diaphragm then stapling was done after. While in group (B) stapling was done after a small opening was made in the greater omentum then dissection of the greater omentum from the stomach was done.

Results: The mean operative time was 63 ( $\pm 16 \mathrm{~min}$ ) for group A and 55 ( $\pm 18 \mathrm{~min}$ ) for group (B). Regarding major perioperative complications there was a case of significant intraoperative bleeding and a case of portal vein thrombosis in group (A), also there was a case of stricture near the incisura in group (B). There was no mortalities in this study. Mean total blood loss was $70+/-11 \mathrm{~mL}$ (group A) and $51+/-9 \mathrm{~mL}$ (group B). Preoperative BMI was $45 \pm 7$ in group (A) which decreased to $30 \pm 6$ after 12 months, while in group(B), preoperative BMI was $46 \pm 5$ decreased to $32 \pm 1$, after 12 months.

Conclusion: In this study we compared results of LSG done by two different techniques either to start by stomach full mobilisation then stapling (A) or stapling then mobilisation of the stomach (B). No major differences were observed between the 2 techniques, however patients in group (B) had a shorter operative time and less blood loss.

Keywords: Morbid obesity, bariatric surgery, sleeve gastrectomy, weight loss.

\section{Introduction}

Obesity is a major worldwide health problem. Surgery is considered superior to medical treatment regarding weight loss in morbidly obese patients. ${ }^{1,2}$

Sleeve gastrectomy is a restrictive weight loss surgery in which $85 \%$ of the stomach is removed leaving a long narrow tube which is the new stomach.The operation started as a part of duodenal switch surgery in 1988. In 2001 sleeve gastrectomy was done as a first stage, followed by gastric bypass in high risk patients.

Today sleeve gastrectomy is the fastest growing weight loss surgery worldwide..$^{3-5}$

In this prospective randomised study we compared two methods for performing laparoscopic sleeve gastrectomy. Devascularisation of the greater curvature is done prior to stapling of the stomach in group (A), while in group (B) stapling of the stomach is done before full mobilisation.

\section{Patients and methods}

This prospective randomised study was conducted in Ain Shams University hospitals from july 2016 to December 2016 after approval of the ethical comittee. The study included 50 patients divided randomly using closed envelope into 2 equal groups, each of 25 patients. Patients with previous operations in the stomach and patients with hiatus hernia were excluded from the study. All the patients had BMI >35, their age ranged from 19 to 58 years. Detailed history was taken from all patients then physical examination was performed.

Full laboratory tests, pelviabdominal ultrasound, chest $X$ ray, ECG, ECHO cardiography and pulmonary function tests were performed for all patients, while upper GI endoscopy was done only in selected patients, according to the history taken. All patients were informed regarding surgical technique and likely complications, and informed consent was obtained from each patient. Prophylactic antibiotics and deep venous thrombosis prophylaxis were given. The patients 
were followed up after one week then 3, 6, 9 and 12 months after surgery.

\section{Surgical Technique}

Under general anaeshesia, patients were positioned with legs apart in anti-Trendelenburgh position. Prophylactic dose of Clexane 40 was received on induction along with a $1 \mathrm{gm}$ ceftriaxone dose. Abdominal insufflation pressure was set at $15 \mathrm{mmHg}$. Five trocars were used and placed as follows: $10-\mathrm{mm}$ camera trocar 2 hand bridth below the xyphoid process, a 5-mm trocar on the left anterior axillary line, a $12-\mathrm{mm}$ trocar on the left midclavicular line between the first and the second trocars, a $12-\mathrm{mm}$ trocar on the right midclavicular line and $5 \mathrm{~mm}$ trocar placed 2 centimeteres below xiphisternum for liver retraction.

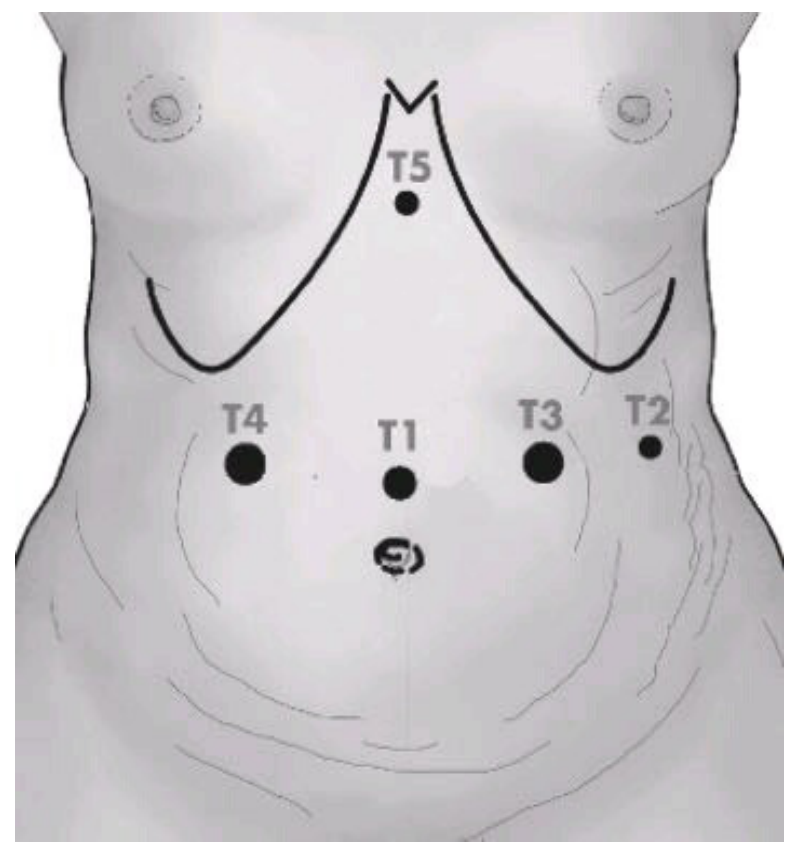

Fig 1: Positioning of trochars for sleeve gastrectomy.

Pylorus is identified then a window is opened in the greater omentum $3 \mathrm{~cm}$ from the pylorus.

\section{Group (A)}

Dissection of the greater omentum was done till reaching left crus of the diaphragm, then stapling was started using a green load (Johnson \& Johnson ( $)$ ) from the right $12 \mathrm{~mm}$ port, $3 \mathrm{~cm}$ from the pylorus over $40 \mathrm{Fr}$ bougie, then stapling was continued using blue loads from the left $12 \mathrm{~mm}$ port till the stomach is separated, taking care that the last staple is $1.5 \mathrm{~cm}$ away from gastroesophogeal junction in order to avoid ischaemia.

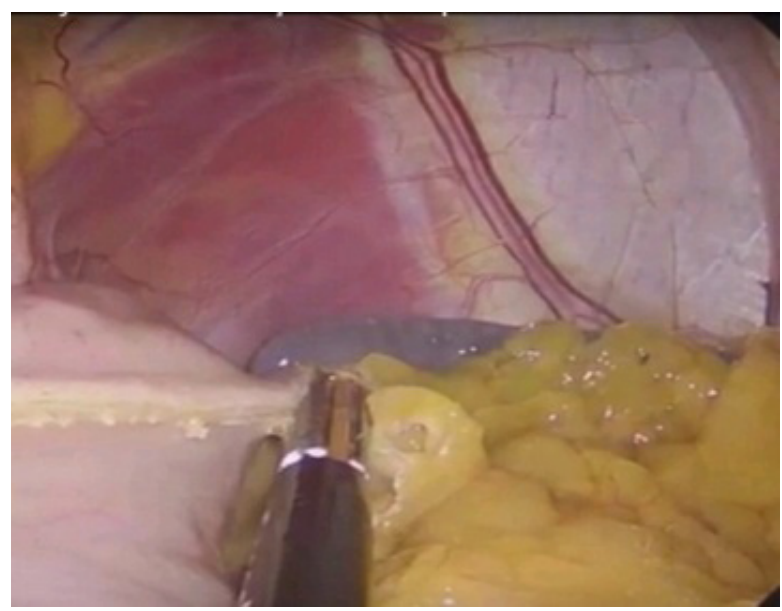

Fig 2: Dissection of greater omentum.

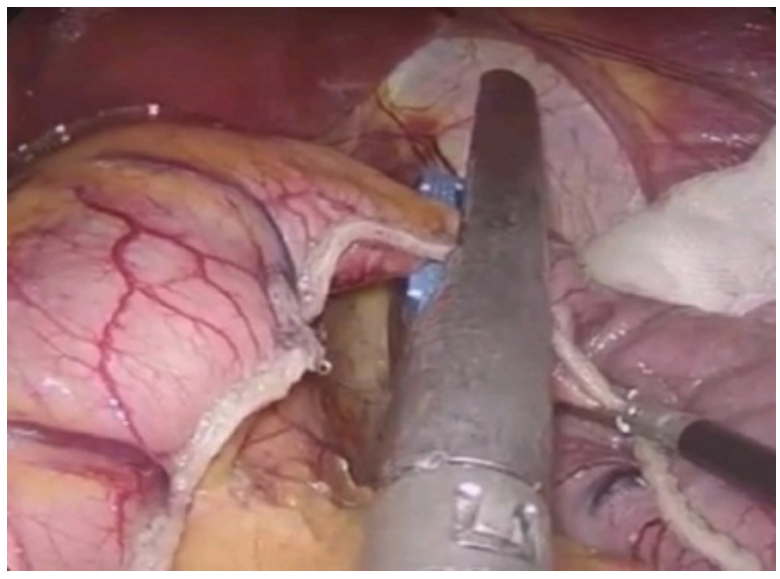

Fig 3: Stapling till stomach is separated.

\section{Group (B)}

$40 \mathrm{Fr}$ bougie was introduced by anaesthisiologist, then stapling was started from the right $12 \mathrm{~mm}$ port using a green load (Johnson \& Johnson $®$ ) and stapling was continued using blue loads from the left $12 \mathrm{~mm}$ port, before the last load, the angle of His was freed in a way similar to that done in gastric bypass surgery using blunt dissection, then the last staple was applied leaving at least $1.5 \mathrm{~cm}$ from the gastroesophogeal junction, then securing the last short gastric vessels from the window in the retro-gastric space was done without division using ligasure $\AA$. After that full dissection of the greater omentum from the resected stomach was done. 


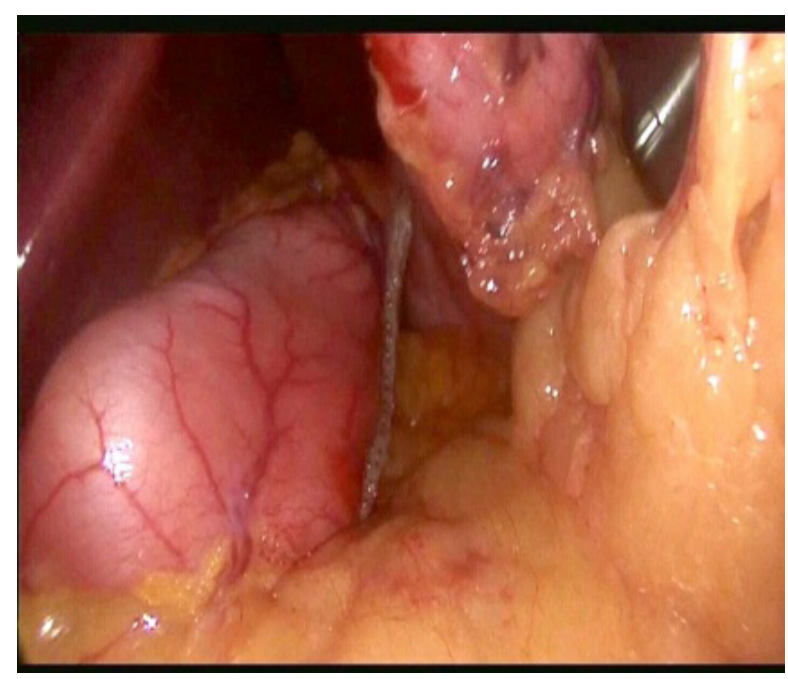

Fig 4: Opening of window in greater omentumandstartstapling.

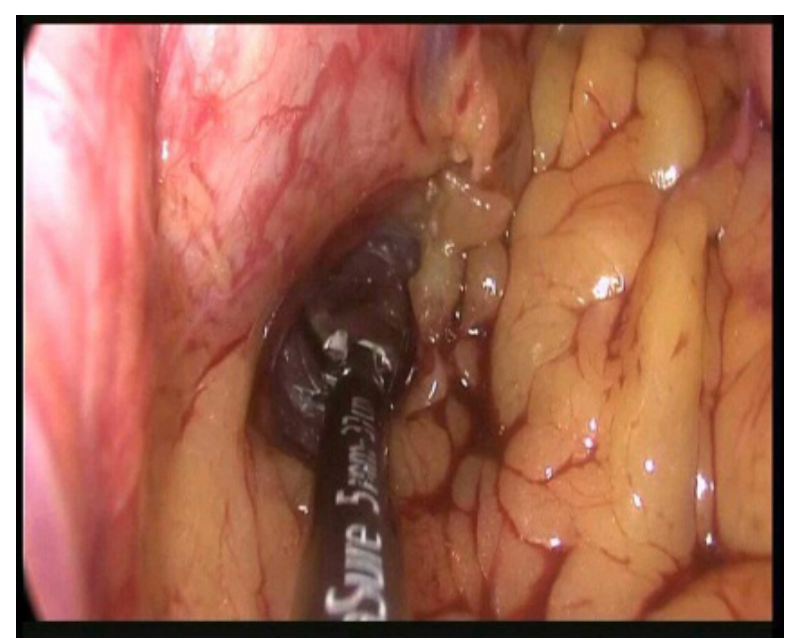

Fig 5: Freeing of the angle of His as done in gastricbypass.

In both groups, the stomach was extracted through one of the $12 \mathrm{~mm}$ ports, then methylene blue test is done. Placing $18 \mathrm{Fr}$ Nelaton drain, closure of muscle at the site of $12 \mathrm{~mm}$ ports was done before skin closure. Patients were kept NPO for $12 \mathrm{~h}$ and on intravenous fluids, antibiotics, analgesics and anticoagulants in a prophylactic dose, gastrograffin study was done in the first postoperative day. Patients were discharged in the first postoperative day after drain removal except for patients with inadequate oral intake, they were discharged in the second postopearative day.

Drugs prescribed for the patients were antibiotics, analgesics, proton pump inhabitors and anticoagulants in the form of clexane 40 for one week. Patients were informed to come for follow up one week after the surgery, then after 3, 6, 9 and 12 months.

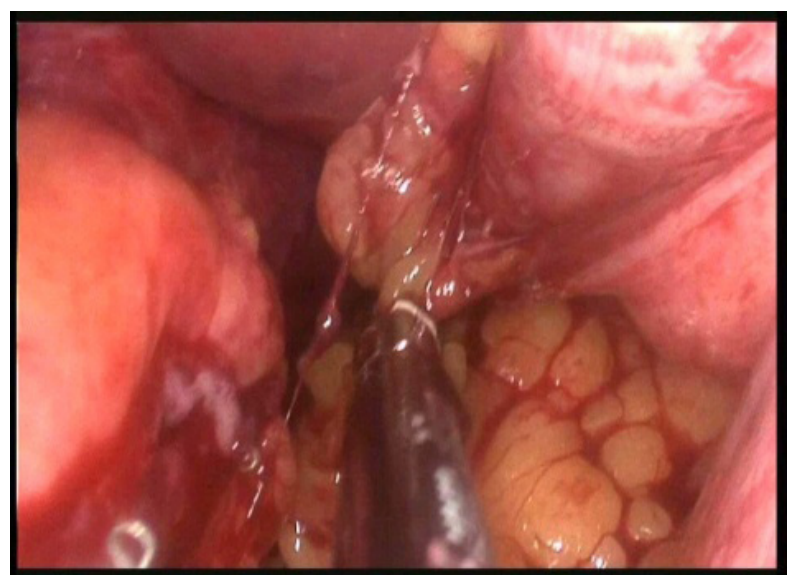

Fig 6: Securing the last short gastrics.

\section{Results}

During the period from July 2016 to December 2016, 50 patients underwent laparoscopic sleeve gastrectomy including 19 males, 38\% (9 in group $A$ and 10 in group $B$ ) and 31 females; 62\% (16 in group $A, 15$ in group $B$ ) with mean age of $37 \pm 16$ years in group $A$ and a mean age of $33 \pm 14$ years in group B. As for comorbidities $3(6 \%)$ patients had diabetes mellitus, 12 (24\%) had hypertension, $6(12 \%)$ had joint pain, and $2(4 \%)$ patients had sleep apnea (Table $\mathbf{1}$ ). The mean operative time was $63 \pm 16$ min for group $A$ and $55 \pm 18$ min for group $(B)(P<0.05=$ significant $)$. There were no conversions in both groups. The patients were followed up until December 2017.

Table 1: Demographics of the patients

\begin{tabular}{lcc}
\hline & A & B \\
\hline Males & 9 & 10 \\
Females & 16 & 15 \\
Mean age & $37 \pm 16$ & $33 \pm 14$ \\
BMI & $45 \pm 7$ & $46 \pm 5$ \\
D.M & 1 & 2 \\
Hypertension & 4 & 8 \\
Joint pain & 4 & 2 \\
Sleep apnea & 1 & 1 \\
\hline
\end{tabular}

There were no mortalities in this study.

Significant bleeding (500 cc) occured from short gastric vessels during omental dissection in one of the cases of group $(A)$, the bleeding site was compressed using a gauze to control bleeding, then the bleeder was clipped.Mean total blood loss was, $70+/-11 \mathrm{~mL}$ (group A) and 51 +/- $9 \mathrm{~mL}$ (group B) $(P<0.05=$ significant $)$. Also there was a case of portal vein thrombosis in group $(A)$ presented on day 28 postoperatively with history of abdominal pain 2 days before. Diagnosis was confirmed by means of C.T pelvi-abdomen with both oral and I.V contrast. The patient received anticoagulant in a therapeutic dose, and the patient was discharged 
after 4 days on oral anticoagulants for 6 months.

There was one case of stricture near the incisura in group (B), which presented one month after the operation. The patient was readmitted and received IV fluids, and was treated by 2 session of endoscopic balloon dilatation, which successefully resolved the condition without the need of further intervention.
There was complete resoulution of diabetes in 2 patients $(66.6 \%)$ and improvment occured in 1 patient (33.3\%). Complete resolution of hypertension occured in 6 (50\%) patients and improved in six (50\%) patients, and joint pain resolved in $5(83.3 \%)$ patients and improved in $1(16.7 \%)$ patient. Sleep apnea resolved in all patients (100\%).

Table 2: Postoperative changes in comorbidities

\begin{tabular}{lcccccc}
\hline Co-morbidities & Gr A pre & \multicolumn{2}{c}{ Gr A post } & Gr B pre & \multicolumn{2}{c}{ Gr B post } \\
\hline & & Resol. & Improv. & & Resol. & Improv. \\
D.M & 1 & 1 & --- & 2 & 1 & 1 \\
Hypertension & 4 & 1 & 3 & 8 & 5 & 1 \\
Jointpain & 4 & 3 & 1 & 2 & 2 & --- \\
Sleep apnea & 1 & 1 & --- & 1 & 1 & --- \\
\hline
\end{tabular}

Preoperative BMI was $45 \pm 7$ in group (A) which decreased to $40 \pm 5,36 \pm 6,33 \pm 5$ and $30 \pm 6 \mathrm{~kg} / \mathrm{m}^{2}$ after $3,6,9$ and 12 months respectively. While in group (B), preoperative BMI was $46 \pm 5$ decreased to $39 \pm 6,37 \pm 5,34 \pm 6$ and $32 \pm 1 \mathrm{~kg} / \mathrm{m}^{2}$, after 3,6 , 9 and 12 months respectively as shown in Figure 7, with $\mathrm{P}>0.05=$ non significant. Mean percentage of EWL (excess weight loss) at 3, 6, 9 and 12 months was $38.2,51.9,64.2$ and $68.9 \%$ for group (A) and 39.2 , 52.6, 65.3, 69.2\% for group (B) respectively with $\mathrm{P}>0.05=$ non significant. The mean hospital stay was $1.5( \pm 0.4)$ days in group (A) and $1.4( \pm 0.5)$ days in group (B).

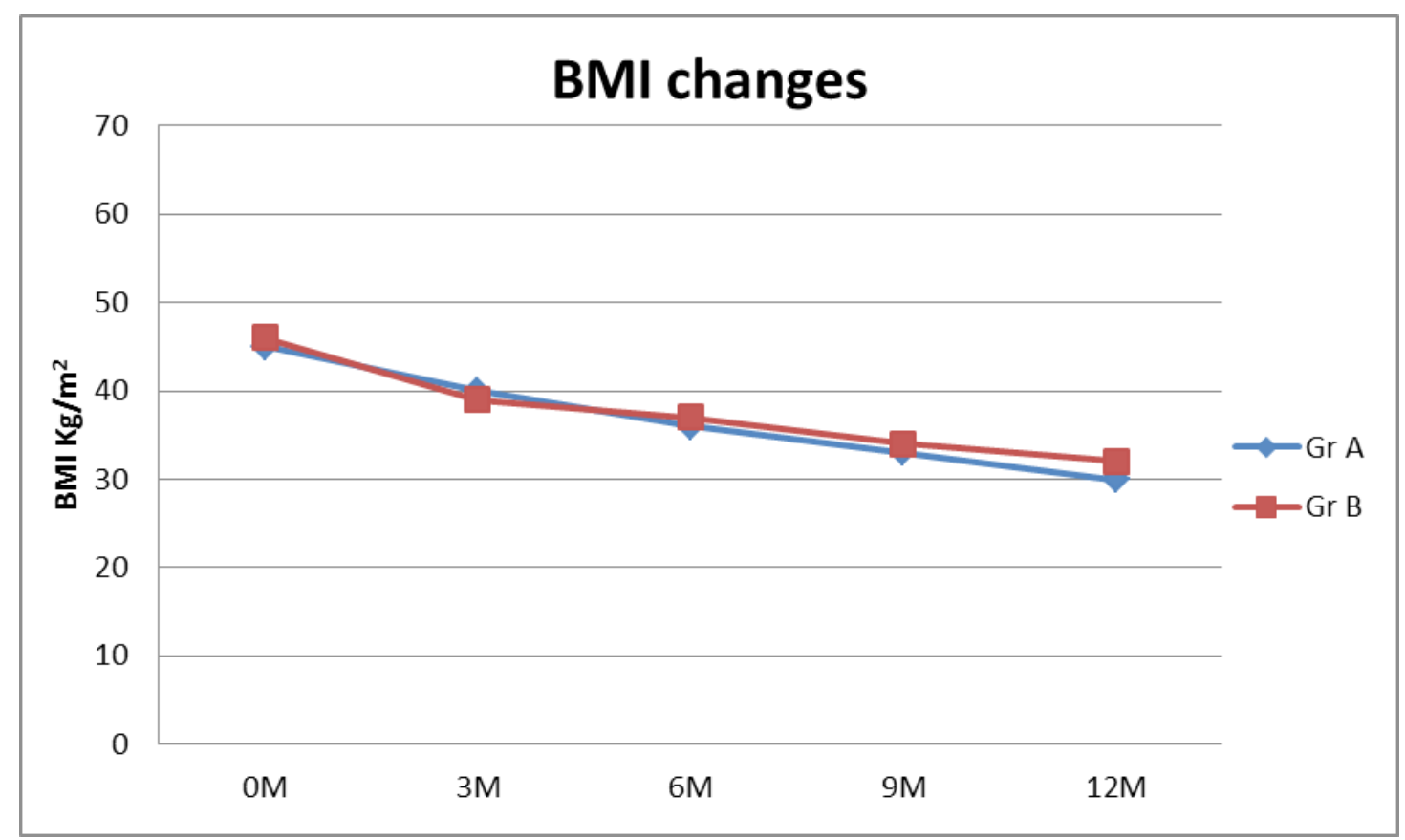

Fig 7: BMI changes. 


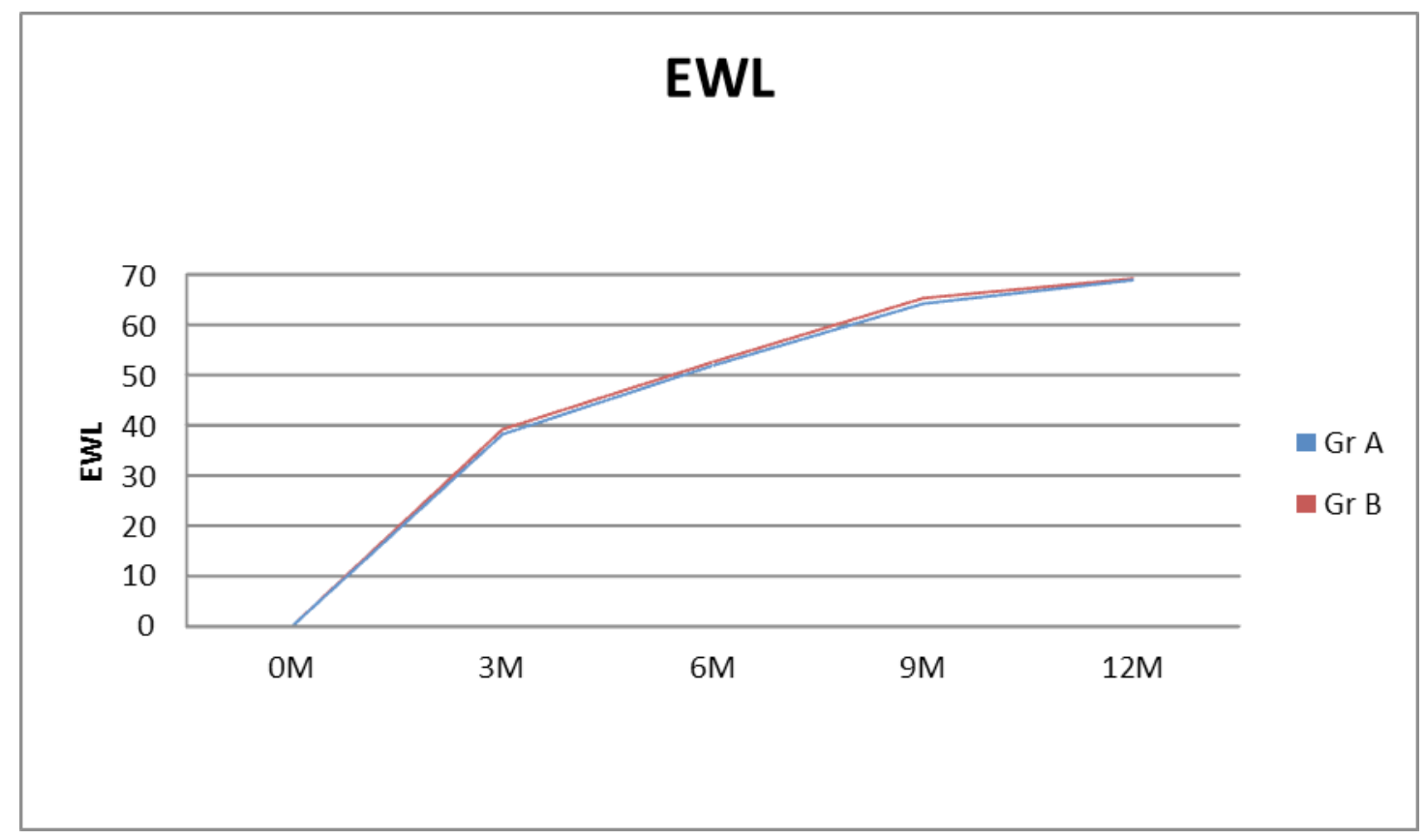

Fig 8: EWL changes.

\section{Discussion}

Sleeve gastrectomy is the commonest bariatric surgery done nowadays. The classic technique starts by full dissection of the greater omentum, starting few centimeters from the pylorus to the left crus of the diaphragm then to start stapling ${ }^{6-8}$ This may carry some technical difficulties in dissecting the connection with the spleen and may increase the risk of bleeding from short gastric vesseles, specially in patients with high $\mathrm{BMI}^{9}{ }^{9}$ while in the modified technique stapling starts directly after opening the window in the greater omentum. After the stapling is completed, the last short gastrics were secured, then dissection of the greater omentum from resected part of the stomach is done, which in our opinion is technically easier and carries less risk of bleeding than the classic method.

In a study done by Dapri comparing the 2 techniques, the median operative time was 25 minutes $^{9-51}$ using the classic technique $(A)$ and 34 minutes $^{12-54}$ using the modified technique (B). While The median hospital stay was 3 days $(\mathrm{I}-10)$ for group (A) and 3 days (2-7) for group (B). As for complications there was a case of intraopearative bleeding $(450 \mathrm{ml})$ in group $(A)$ and case of leak at the angle of His in group (A). ${ }^{10}$ while in our study the mean operative time for group (A) was 63 ( $\pm 16 \mathrm{~min}$ ) while it was 55 ( $\pm 18 \mathrm{~min}$ ) for group $B$. Also the mean hospital stay was $1.5( \pm 0.4)$ days in group (A) and $1.4( \pm 0.5)$ days in group (B). As for complications in this study there was a case of significant bleeding $(500 \mathrm{cc})$ from short gastrics in group (A). Also there was a case of portal vein thrombosis in group (A) and there was a case of stricture near the incisura in group (B).

Mean percentage of EWL (excess weight loss) at $3,6,9$ and 12 months was 38.2, 51.9, 64.2 and $68.9 \%$ for group (A) and and 39.2, 52.6, 65.3, $69.2 \%$ for group (B) respectively which was lower than results of Maryam et al where the percentage of excess weight loss 3,6 , and 12 months were $42.6 \%, 57.5 \%$, and $80.7 \%$ in the LSG. This may be attributed to smaller bougie size which was 36 $\mathrm{F}$ compared to $40 \mathrm{~F}$ in our study and also to the tightening sutures applied in his study. ${ }^{10}$

In our study there was a slight, but statistically significant difference between both groups regarding the operative blood loss and the operative time in favour of group B but there were no statistical differences regarding the hospital stay, BMI changes and EWL. Thus the forementioned technique seems to be safe and effective technique for performing sleeve gastrectomy in morbidly obese patients when compared to the original technique.

\section{Refrences}

1. Obesity preventing and managing the global epidemic: Report of a WHO consultation. World Health Organ Tech Rep Ser. 2000; 894: i-xii, 1-253.

2. Haslam DW, James WP. Obesity. Lancet. 2005; 366: 1197-1209.

3. Hubert HB, Feinleib M, McNamara PM, Castelli 
WP: Obesity as an independent risk factor for cardiovascular disease: A 26-year follow-up of participants in the Framingham Heart Study. Circulation. 1983; 67: 968-977.

4. Ejerblad E, Fored CM, Lindblad P, Fryzek J, McLaughlin JK, Nyrén O: Obesity and risk for chronic renal failure. J Am Soc Nephrol. 2006; 17: $1695-1702$.

5. W. J. Pories, M. S. Swanson, K. G. Mac Donald et al.: Who would have thought it? An operation proves to be the most effective therapy for adult-onset diabetes mellitus. Annals of Surgery. 1995; 222: 339-352.

6. Gagner M, Inabnet WB, Pomp A: Laparoscopic sleeve gastrectomy with second stage biliopancreatic diversion and duodenal switch in the superobese. In: Inabnet WB, DeMaria EJ, Ikramuddin S, eds. Laparoscopic bariatric surgery. Philadelphia: Lippincott William \& Wilkins. 2005: 143-50.

7. Silecchia GF, Boru C, Pecchia A et al: Effectiveness of laparoscopic sleeve gastrectomy (first stage of biliopancreatic diversion with duodenal switch) on comorbidities in super-obese high risk patients. Obes Surg. 2006; 16: 1138-44.

8. Mognol P, Chosidow D, Marmuse JP: Laparoscopic sleeve gastrectomy as an initial bariatric operation for high-risk patients: Initial results in 10 patients. Obes Surg. 2005; 15: $1030-3$.

9. Almogy G, Crookes PF, Anthone GJ: Longitudinal gastrectomy as a treatment for the high-risk super- obese patient. Obes Surg. 2004; 14: 492-7.

10. Dapri G, Vaz C, Cadière GB, Himpens J: A prospective randomized study comparing two different techniques for laparoscopic sleeve gastrectomy. Obesity Surgery. 2007; 17: 1435-1441.

11. Barzin M, Khalaj A, Motamedi MA, Shapoori P, Azizi F, Hosseinpanah F: Safety and effectiveness of sleeve gastrectomy versus gastric bypass: One-year results of Tehran Obesity Treatment Study (TOTS). Gastroenterol Hepatol Bed Bench. 2016; 9: 62-69. 


\title{
Bipolar Coagulation versus Ultrasonic Dissection Devices in Laparoscopic Sleeve Gastrectomy
}

\author{
Ahmed A Sabry, Saleh MY \\ Department of Surgery, Faculty of Medicine, Alexandria University, Egypt
}

Laparoscopic sleeve gastrectomy (LSG) comprises the first choice for treating morbid obesity in many bariatric centers. In the era of modern laparoscopic techniques and minimally invasive surgery, tying and knots have a limited role. New devices as ultrasonic and electrothermal bipolar have evolved in order to achieve adequate haemostasis, tissue dissection and coagulation with reduced operating times. The aim of this study was to compare the usage of Ligasure as one of the electrothermal bipolar devices and Harmonic scalpel as one of the ultrasonic devices in devascularization of the greater curvature of the stomach during LSG as regard the operative time and intra-operative and postoperative complications. There were no statistically significant difference in the operative time and complications between both groups. The mean operative time in Ligasure group was $100.50 \pm 15.95$ minutes and in Harmonic group mean 97.71 \pm 8.21 minutes. Both Ligasure and Harmonic provide the surgeon comfort, time saving, safety and efficacy in such a demanding operation. Choice between these two devices lies within the surgeon's preference.

Key words: Sleeve gastrectomy, bariatric surgery, Harmonic, Ligasure.

\begin{abstract}
Introduction
Laparoscopic sleeve gastrectomy (LSG) was introduced by Gagner and colleagues ${ }^{1}$ in 2000 as a first-step procedure to minimize surgical risk for super-obese or high-risk patients. ${ }^{1,2}$ Today, laparoscopic sleeve gastrectomy is gaining popularity because of its relative simplicity, the great results over the years, the less technical demands and the small learning curve. Sleeve gastrectomy comprises the first choice for treating morbid obesity in many bariatric centers. ${ }^{3}$
\end{abstract}

The operation begins with devascularization of the greater curvature of the stomach, with division of the short gastric vessels using one of vascular sealing devices. The most popular sealing devices are bipolar electrosurgical and Ultrasonic dissection devices.

The electrothermal bipolar vessel sealing (EBVS) systems are a modification of the bipolar electrosurgical technology developed in the 1940s. In 1984 a team of neurosurgeons from Sweden introduced a modification to reduce the inadvertent burning and charring produced by these systems. ${ }^{4}$ This was accomplished by incorporating a computer algorithm monitoring the impedance between the jaws of the instruments in real time. In 1998, a computer algorithm used to monitor the impedance in an instrument designed as clamp, this first EBVS system allowed for blood vessel of up to $7 \mathrm{~mm}$ to be sealed. ${ }^{5}$ The instrument is usually designed as a clamp e.g.: Ligasure Atlas.
The basic working principle of ultrasonic surgical instruments, such as ultrasonically activated scalpel (UAS) is to use the low-frequency mechanical vibrations produced by the piezoelectric transducers embedded in the tools that convert the applied electrical energy to mechanical vibrations, which are then transferred to the active blades which induce protein denaturation by breaking down the hydrogen bonds in tissues due to the internal cellular friction caused by the vibrations for cutting or coagulation. The Harmonic scalpel is one of these devices which operates at a frequency of $55.5 \mathrm{kHz}{ }^{6}$

\section{Patients and methods}

This study was carried out on 37 morbidly obese patients that were randomly divided in to two groups according to the type of the sealing device used. The Ligasure group contained 20 patients, while the Harmonic group contained 17 patients. All operations were performed under general anesthesia. Intra-operatively, we recorded the operative time, any difficulties and intraoperative complications such as bleeding, hematoma formation, leakage and organ injury. Postoperatively, all the patients were assessed postoperatively as regards the length of postoperative hospital stay, postoperative complications such as hemorrhage, hematoma formation, leakage, abscess formation, collection formation, fever $>38$ ỏC.

\section{Results}

The patients in this study were 37 patients. The 
Ligasure group contained 20 patients, 17 females (85\%) and 3 males (15\%) aged from 19 to 55 years with mean $36.65 \pm 10.10$ years and the Harmonic group contained 17 patients, 12 females (70.6\%) and 5 males (29.4\%) aged from 22 to 49 years with mean $34.88 \pm 8.07$ years. In the Ligasure group the mean patients' BMIs was $50.55 \pm 4.63$ $\mathrm{kg} / \mathrm{m}^{2}$ and in the Harmonic group the patients' was mean $49.64 \pm 5.74 \mathrm{~kg} / \mathrm{m}^{2}$.

The operative time in the Ligasure group ranged from 82.0 to 162.0 minutes with mean $100.50 \pm 15.95$ minutes and in the Harmonic group ranged from 85.0 to 120.0 minutes with mean $97.71 \pm 8.21$ minutes.

The time of devascularization of greater curvature in Ligasure group ranged from 19.0 to 35.0 minutes with mean $23.70 \pm 3.50$ minutes while in Harmonic group ranged from 17.0 to 25.0 minutes with mean $22.59 \pm 2.27$ minutes.

Almost all of the cases had no intraoperative complications except in 2 cases $(10 \%)$ of the Ligasure group when we faced difficulty in devascularization of the gastrosplenic ligament that caused an injury to the splenic capsule, both were controlled by application of absorbable hemostat (Surgicel ${ }^{\circledR}$ ). Regarding the intraoperative bleeding from the staple line we had (two cases of Ligasure group vs. one case of Harmonic group) all of them were controlled by clipping the staple-line. Regarding the hematoma formation we noted one case in each group that were controlled by suction irrigation then good hemostasis by the device itself. No intraoperative leakage was detected in both groups.

Postoperative complications were observed from day 1 till the patients were discharged from the hospital.

In Ligasure group one case suffered from bloody discharge from the abdominal drain about $300 \mathrm{cc}$ which was managed by supportive measures with no need for exploration, another case suffered from leakage and intraperitoneal abscess formation which was managed by endoscopic mega stent insertion for the leakage with pigtail insertion in the collection, and two cases complained of low grade fever around $38.5^{\circ} \mathrm{C}$. In Harmonic group there were no postoperative complications except two cases that suffered from fever around $38.5^{\circ} \mathrm{C}$.

In Ligasure group the postoperative hospital stay ranged from 2.0 to 21.0 days with mean $3.90 \pm 4.10$ days and in harmonic group ranged from 2.0 to 4.0 with mean $3.0 \pm 0.50$

\section{Discussion}

Our results in this study are almost the same as the study of Tsamis et $\mathrm{al}^{3}$ in 2015 that compared the usage of the Ligasure and Harmonic scalpel in LSG that included 94 patients of which $37.2 \%$ were men and $62.8 \%$ were women. Forty three of them were operated on using Ligasure and the other 51 patients were operated on using Harmonic scalpel. ${ }^{3}$ the total number of the our patients was 37 patients 8 of them $(21.7 \%)$ were males and 29 $(78 \%)$ were females, 20 patients were operated on using Ligasure and the other 17 patients were operated on using Harmonic scalpel.

In our Ligasure group the patients' mean BMI was $50.55 \pm 4.63 \mathrm{~kg} / \mathrm{m}^{2}$ and in Harmonic group was $49.64 \pm 5.74 \mathrm{~kg} / \mathrm{m}^{2}$, while in Tsamis et $\mathrm{al}^{3}$ the mean BMI in Ligasure group was $45.2 \pm 8 \mathrm{~kg} / \mathrm{m}^{2}$ and in Harmonic group was $45.7 \pm 6.07 \mathrm{~kg} / \mathrm{m}^{2}$. $^{3}$

Our mean operative time in Ligasure group was slightly higher than Harmonic group (100.50 \pm 15.95 vs $97.71 \pm 8.21 \mathrm{~min}, \mathrm{p}=0.519$ ) which showed no significant difference. Overall our operative time is much higher than Tsamis et $\mathrm{al}^{3}$ which also did not significantly differ between both groups (45.0 \pm 15.0 vs $40.0 \pm 20.0 \mathrm{~min}, \mathrm{p}=0.199){ }^{3}$

The difference in the mean operative time is most probably due to low BMI of the patients, the large number of cases and surgeons' experience in Tsamis et al ${ }^{3}$ study.

Overall intraoperative complications in our both groups showed no statistically significant difference ( $25 \%$ vs. $11.7 \%$ with $p=0.800$ ) as well as there was no significant difference in both groups as regard the post-operative complications ( $25 \%$ vs. $11.7 \%$ with $p=1.000$ ) This result is compareble to Tsamis et $\mathrm{al}^{3}$ study which also showed no statistically significant differences between these two devices. But a trend for more intraoperative complications was seen in the group operated on by Ligasure ( 32.6 vs. $15.7 \%, p=0.054$ ), and a trend for more postoperative complications was revealed for Harmonic scalpel group (4.7 vs. 17.6 $\%, p=0.051) .^{3}$ Overall our intraoperative and post-operative complications compared to those of Tsamis et $\mathrm{al}^{3}$ are summarized in Table $\mathbf{I}$. 
Table I Comparison between our study and the study of Tsamis et $\mathrm{al}^{3}$

\begin{tabular}{|c|c|c|c|c|c|c|}
\hline \multicolumn{3}{|c|}{ Our Study } & \multicolumn{4}{|c|}{ Tsamis et al } \\
\hline \multirow{2}{*}{ Complications } & Ligasure & Harmonic & \multirow{2}{*}{ FEp } & Ligasure & Harmonic & \multirow{2}{*}{${ }^{\mathrm{FE}} \mathbf{p}$} \\
\hline & No. (\%) & No. (\%) & & No. (\%) & No. (\%) & \\
\hline Intraoperative & $5(25 \%)$ & $2(11.7 \%)$ & 0.800 & $14(32.6 \%)$ & $8(15.7 \%)$ & 0.054 \\
\hline Bleeding & $2(10 \%)$ & $1(5.9 \%)$ & 1.000 & $10(23.3 \%)$ & $8(15.7 \%)$ & 0.353 \\
\hline Hematoma formation & $1(5 \%)$ & $1(5.9 \%)$ & 1.000 & $2(4.7 \%)$ & $0(0 \%)$ & 0.207 \\
\hline Organ injury & $2(10 \%)$ & $0(0 \%)$ & 0.489 & $1(2.3 \%)$ & $0(0 \%)$ & 0.999 \\
\hline Leakage & 0 & $0(0 \%)$ & - & $1(2.3 \%)$ & $0(0 \%)$ & 0.457 \\
\hline Postoperative & $5(25 \%)$ & $2(11.7 \%)$ & 1.000 & $2(4.7 \%)$ & $9(17.9 \%)$ & 0.051 \\
\hline bleeding & $1(5 \%)$ & $0(0 \%)$ & 1.000 & $3(5.9 \%)$ & 0.247 & 0.247 \\
\hline Hematoma formation & $0(0 \%)$ & $0(0 \%)$ & - & $0(0 \%)$ & $0(0 \%)$ & - \\
\hline Leakage & $1(5 \%)$ & $0(0 \%)$ & 1.000 & $0(0 \%)$ & $0(0 \%)$ & - \\
\hline Abscess formation & $1(5 \%)$ & $0(0 \%)$ & 1.000 & $1(2.3 \%)$ & $2(3.9 \%)$ & 0.999 \\
\hline Collection formation & $0(0 \%)$ & $0(0 \%)$ & - & $0(0 \%)$ & $1(2.0 \%)$ & 0.999 \\
\hline Fever $>380 ̉ C$ & $2(10 \%)$ & $2(11.8 \%)$ & 1.000 & $1(2.3 \%)$ & 0.622 & 0.622 \\
\hline
\end{tabular}

The issue of safety and efficacy of both devices is more studied in thyroid surgery and less in haemorrhoidectomy, but there are also few studies examining laparoscopic colectomies. In most of these studies comparing the two shears, there are no significant differences in complication rates, operative time, pain medication requirements and total cost.7,8 When both of these vessel sealing systems are compared with conventional thyroidectomy techniques, they display reduced operative time, less blood loss, smaller incision length, shorter length of hospital stay, less postoperative pain and similar complication rates. ${ }^{9,}{ }^{10}$ A large meta-analysis from Garas et al. in 2013 revealed that Harmonic scalpel had lower risk for postoperative hypoparathyroidism than Ligasure, but both shears had recurrent laryngeal nerve paralysis more often than clamp-and-tie technique. $^{7}$

In laparoscopic colorectal surgery, some nonrandomized studies tended to show comparable results of Ligasure and Harmonic scalpel in complication rate and operative time. ${ }^{11}$ Later, randomized studies like the one from Rimonda et al. with 140 consecutive patients failed to show a significant difference in terms of intraoperative and postoperative complications and operative time. ${ }^{12}$ In fact, other studies as Campagnacci et a ${ }^{13}$ and Takada et al ${ }^{14}$ also failed to show clear advantages of Ligasure device over Harmonic scalpels in laparoscopic colorectal surgery. ${ }^{13,14}$

\section{Conclusions}

In conclusion this prospective randomized study failed to demonstrate any statistically significant advantage of the Ligasure or the Harmonic in laparoscopic sleeve gastrectomy in terms of operative time, and complications. Both Ligasure and Harmonic provide the surgeon comfort, time saving, safety and efficacy in such a demanding operation. Choice between these two devices lies within the surgeon's preference.

\section{References}

1. Lakdawala MA, Bhasker A, Mulchandani D, Goel S, Jain S: Comparison between the results of laparoscopic sleeve gastrectomy and laparoscopic Roux-en-Y gastric bypass in the Indian population: A retrospective 1 year study. Obes Surg. 2010; 20: 1-6.

2. Srinivasa S, Hill LS, Sammour T, Hill AG, Babor $\mathrm{R}$, Rahman H: Early and mid-term outcomes of single-stage laparoscopic sleeve gastrectomy. Obes Surg. 2010; 20: 1484-90.

3. Tsamis D, Natoudi M, Arapaki A, Flessas I, Papailiou I, Bramis K, et al: Using Ligasure or Harmonic $A c e(R)$ in laparoscopic sleeve gastrectomies? A prospective randomized study. Obes Surg. 2015; 25: 1454-7.

4. Vallfors B, Bergdahl B: Automatically controlled bipolar electrocoagulation--"COA-COMP". Neurosurg Rev. 1984; 7: 187-9.

5. Kennedy JS, Stranahan PL, Taylor KD, Chandler JG: High-burst-strength, feedback-controlled bipolar vessel sealing. Surg Endosc. 1998; 12: 
876-8.

6. Sankaranarayanan G, Resapu RR, Jones DB, Schwaitzberg S, De S: Common uses and cited complications of energy in surgery. Surg Endosc. 2013; 27: 3056-72.

7. Garas G, Okabayashi K, Ashrafian H, Shetty K, Palazzo $\mathrm{F}$, Tolley $\mathrm{N}$, et al: Which hemostatic device in thyroid surgery? A network metaanalysis of surgical technologies. Thyroid. 2013; 23: 1138-50.

8. Kwok SY, Chung CC, Tsui KK, Li MK: A doubleblind, randomized trial comparing Ligasure and Harmonic Scalpel hemorrhoidectomy. Dis Colon Rectum. 2005; 48: 344-8.

9. Miccoli $P$, Berti $P$, Dionigi G, D'Agostino J, Orlandini C, Donatini G: Randomized controlled trial of harmonic scalpel use during thyroidectomy. Arch Otolaryngol Head Neck Surg. 2006; 132: 1069-73.

10. Petrakis IE, Kogerakis NE, Lasithiotakis KG, Vrachassotakis N, Chalkiadakis GE: LigaSure versus clamp-and-tie thyroidectomy for benign nodular disease. Head Neck. 2004; 26: 903-9.

11. Heniford $B T$, Matthews $B D$, Sing RF, Backus C, Pratt B, Greene FL: Initial results with an electrothermal bipolar vessel sealer. Surg Endosc. 2001; 15: 799-801.

12. Rimonda R, Arezzo A, Garrone C, Allaix ME, Giraudo G, Morino M: Electrothermal bipolar vessel sealing system vs. harmonic scalpel in colorectal laparoscopic surgery: A prospective, randomized study. Dis Colon Rectum. 2009 52: 657-61.

13. Campagnacci $R$, de Sanctis $A$, Baldarelli $M$, Rimini $M$, Lezoche $G$, Guerrieri $M$ : Electrothermal bipolar vessel sealing device vs. ultrasonic coagulating shears in laparoscopic colectomies: A comparative study. Surg Endosc. 2007; 21: 1526-31.

14. Takada M, Ichihara T, Kuroda Y: Comparative study of electrothermal bipolar vessel sealer and ultrasonic coagulating shears in laparoscopic colectomy. Surg Endosc. 2005; 19: $226-8$. 